\title{
Os esvaziamentos do ator e da cena no teatro de Peter Broolk
}

Larissa Elias*

No filme-documentário Brook par Brook, de seu filho, Simon ${ }^{1}$, Peter Brook mostra uma escultura pré-colombiana que ele chama de Mulher Sorridente. Ele diz que, no início dos ensaios, sempre mostra aquela imagem para os atores porque ela traduz o esvaziamento. E diz ainda que a mulher tem uma expressão de puro júbilo, e que isso é como o ator se esvaziando. Em O Ponto de Mudança, ele descreve a escultura:

Tenho uma pequena estátua de Vera Cruz, representando uma deusa com a cabeça jogada para trás e as mãos erguidas - tão perfeita em sua concepção, proporção e forma, que a figura expressa uma espécie de radiância interior. Para ter sido capaz de criá-la, o artista deve ter experimentado essa radiância. Contudo, não procurou descrever radiância para nós por meio de um conjunto de símbolos abstratos. Não nos contou nada: apenas criou um objeto que concretiza essa qualidade específica. No meu entender, tal é a essência da grande representação. (BROOK, 1994: 306-307)

Meierhold afirma que para improvisar o ator precisa estar alegre: "O ator só é capaz de improvisar quando se sentir alegre interiormente. Fora da atmosfera da alegria criadora, do júbilo artístico, o ator não se descobre nunca em sua plenitude" (CONRADO, 1969: 197). Alegria ou júbilo, vazio, plenitude e improvisação, para Brook e Meierhold, são idéias entrelaçadas. A Mulher Sorridente é uma figura estilizada de mulher, cuja aparência poderia ser comparada à rudeza de um desenho infantil. Os traços da escultura são os minimamente necessários para expressar seu estado de contentamento. No mesmo texto em que se refere à escultura, Brook fala que se tivesse uma escola de teatro começaria por coisas básicas: "iniciaríamos a estudar como

*Larissa Elias, atriz, integrante de Os Cênicos Cia. de Teatro. Mestre em Teatro pela UNIRIO, com dissertação sobre Peter Brook, atualmente cursando o doutorado. 
sentar, como ficar de pé, como levantar um braço [...] estaríamos apenas aprendendo a ser atores" (BROOK, 1994:307). A Mulher Sorridente é, para Brook, uma representação simbólica do ator vazio, isto é, aberto, disponível, pronto para expressar uma imagem. Em sua percepção o vazio visa a plenitude e a plenitude é como o vazio: inesgotável. Esta pode ser considerada uma noção ampla de ator vazio, que na prática se concretiza através de uma série de aspectos técnicos.

No documentário, Peter Brook explica qual é, para ele, a diferença entre a improvisação que se faz no Actor's Studio, em Nova York, baseada no método de Stanislavski², e a improvisação que ele mesmo faz. Na improvisação do Actor's o professor, ou o diretor, diz para o ator quem é o personagem, em que circunstâncias ele se encontra, qual a sua história passada, qual a situação do momento e manda ele improvisar. $O$ ator entra em cena cheio de idéias previamente concebidas. Já na sua improvisação, ele entrega um sapato para o ator e diz: improvise. O ponto de partida é um vazio, é Brook quem fala.

Não vou me aprofundar nas questões relativas ao sistema de Stanislavski, mas vale ressaltar que suas pesquisas sobre o ator tiveram várias fases, e seu método, ao longo do tempo em que produziu, passou por muitas transformações. Deve-se, portanto, distinguir a dinâmica da sua metodologia das leituras posteriores que se fizeram dela. Em agosto de 2002, fiz uma oficina com Valentin Tepliakov, professor da Academia Russa de Arte Teatral, cujo programa curricular é também baseado no método de Stanislavski. As improvisações que ele nos propunha fazer eram do mesmo teor da improvisação do Actor's Studio, descrita por Brook.

Pode-se ir muito longe na elaboração prévia desse tipo de improvisação, havendo ou não um texto como base. Se houver um texto as informações serão buscadas nele, se não elas serão inventadas pelo ator e/ou o diretor. As improvisações na oficina de Valentin Tepliakov eram mais ou menos assim: dois atores criavam intelectualmente uma situação e um contexto. Por exemplo: um casal em crise. A mulher, médica, 45 anos, independente financeiramente, se torna amante do diretor do hospital onde trabalha. O marido também médico, 47 anos, é um pai ausente e exagera na bebida. O casal tem três filhos etc. Dado o contexto, a ação é: o casal vai se encontrar num bar e o marido vai revelar que descobriu o amante. O que acontecia era improviso, mas os atores já entravam em cena com muitas idéias prontas, e sua tendência, neste caso específico, foi falar exasperadamente tentando informar ao público toda aquela história.

Isso é tudo o que Peter Brook tenta evitar. Ele aposta no contrário disso. 
Ou seja, que a história, as emoções, os sentidos, tudo, enfim, se estabeleça a partir da relação concreta entre os atores, em cena. E o começo pode ser qualquer coisa. Fiz uma outra oficina, em junho de 2002, com a atriz Lilo Baur, que atuava na montagem de A Tragédia de Hamlet de Peter Brook, em turnê pelo Rio de Janeiro, nessa época. Uma das improvisações que fizemos era a seguinte: dois atores se encontravam, se sentavam e se cumprimentavam com um "Bom dia". De cada encontro surgia uma história diferente.

O modo como os atores sentavam, o tempo que cada um levava para dizer "Bom dia", a respiração, as pausas, se o "Bom dia" era repetido uma, duas, três vezes ou mais, por cada ator, o modo de um ator olhar para o outro, se os atores olhavam para a platéia, a reação da platéia, que por sua vez, gerava no ator uma nova reação, se um ator sentava e levantava, e repetia algumas vezes essa ação: a variação desses elementos, e tantos outros que apareceram na hora, multiplicavam as histórias, os personagens e as impressões. Nada era previamente elaborado. Tudo acontecia no ato, a partir da relação dos atores entre si e destes com os espectadores.

Brook fala de uma improvisação, feita por uma atriz do $\mathrm{CIRT}^{3}$, num albergue português, em Paris, bastante significativa:

Miriam Goldschmidt [...] sem pensar levanta o seu dedo polegar e subitamente descobre, a partir da reação do público, que ela na verdade está pedindo carona a um caminhão; então, instantaneamente, ela representa o papel de alguém que pede carona, e isso naturalmente se desenvolve em uma saga da imigração que envolve todos na sala (BROOK, 2000: 242-243).

Nestas duas últimas improvisações descritas, há apenas um fragmento, um tema, um gesto ou uma palavra a partir do que se improvisa. É o ator e uma ação; o ator e um objeto; o ator e uma palavra, às vezes só o ator, que caminha e... acontece alguma coisa, e outra e assim por diante. Mas isso nem sempre acontece e a improvisação pode ser um desastre, esse é um grande risco que se corre. Uma boa improvisação raramente se repete, e, geralmente, não se sustenta por muito tempo.

A utilização do silêncio é também uma forma de esvaziamento. Ficar em silêncio e sustentar esse estado não é uma tarefa fácil para o ator. O exercício de ficar parado, em silêncio, olhando para um outro ator, ou diante de uma platéia, é um desafio, por vezes, sufocante, e que exige treinamento. Exercícios com pausas, fala muito rápida ou muito lenta, assim como uma série de outros exercícios, aparentemente formais por não terem relação direta com os sentidos do texto, podem, pelo fato de retirarem o ator do modo cotidiano de se comportar e de falar, e justamente por não se relacionarem 
aos sentidos, também aparentes, do texto, abrir um universo de significados e possibilidades antes invisíveis, inaudíveis e imperceptíveis.

Em um de seus primeiros trabalhos experimentais, o Teatro da crueldade, de 1964, Brook fez o que considera um de seus exercícios mais importantes: um ator sentava-se no palco, de costas para o público, e ficava durante quatro ou cinco minutos sem fazer nada. Foi a partir dele que Brook pôde entender a qualidade do próprio evento, realizado na imediatez daquele instante por um ator, cuja força era inseparável da relação com a platéia.

Nessa experiência importava questionar todas as convenções, e importava antes conhecer a reação do público, saber quais os pontos de convergência entre os espectadores e os atores. Era o jogo entre esses organismos vivos que estava sendo profundamente explorado. A cada passo Brook retinha mais fortemente a idéia de que tanto mais aberto o campo - e isso significava um espaço teatral vazio, e isto vai então significar um ator vazio -, mais livre era o jogo do imaginário e mais intensa a relação entre ator e espectador.

Experimentar uma nova forma teatral objetivava uma relação nova com o espectador, e isso implicava mudar os contextos, e para mudar os contextos era preciso deslocar-se. Viajar tornou-se uma necessidade para as pesquisas de Brook e seu grupo internacional de atores. Eles foram para a África e para os Estados Unidos, onde fizeram uma espécie de teatro improvisacional, os carpet shows ou espetáculos do tapete. Esse foi o caminho para a descoberta de uma forma viva e original de fazer teatro. A improvisação e os exercícios eram uma maneira de escapar do teatro morto, nos dois principais sentidos que Brook dá a esse termo, quais sejam, um mau teatro e um teatro que começa a morrer no dia em que nasce. Seu objetivo era "confrontar o ator o tempo todo com suas próprias barreiras, nos pontos em que, no lugar da verdade de uma nova descoberta, ele coloca uma mentira" (BROOK, 2000: 119).

Improvisar e fazer exercícios são formas de pesquisa, formas de o ator se preparar e aprimorar seu instrumento, que é ele mesmo, seu corpo, sua voz, seus pensamentos, suas emoções. A improvisação e os exercícios podem ser tanto um meio, um processo para feitura de um espetáculo, como podem ser o próprio espetáculo, como foram os carpet shows, que eram um tipo de teatro improvisacional. Neste caso o próprio processo é exposto, e por isso os carpet são uma radicalização do vazio. Nas improvisações sobre o tapete o ponto de partida é o "zero", no mesmo sentido que no início dos ensaios para uma peça teatral, que irá posteriormente ser fixada, dever-seia partir do "zero", do "vazio". Partir do vazio, significa, antes, partir de um 
ponto infinito de possibilidades. Mas essa é na verdade a intenção. Não significa que seja fácil ou mesmo possível de se conseguir, ao contrário, é muito difícil. Partir do vazio requer um longo e rigoroso aprendizado. Manter potencialmente o vazio numa experiência exige mais ainda do ator. Exige que ele aprenda a repetir diferente. Todos os atores, de qualquer tipo de linguagem ou tradição, sabem que uma apresentação nunca é igual à outra. Isso é quase um chavão no mundo teatral. Uma coisa nunca é idêntica à outra, pois a vida é um devir e não há repetição no tempo. A premissa pode ser verdadeira, mas exercê-la é uma tarefa complexa e muito sutil.

Retirar excessos e provocar rupturas geram um deslocamento que permite um permanente ajuste de posição, e que pode, efetivamente, criar uma relação dinâmica e viva entre o teatro e o seu público. Isso pode ocorrer propositadamente, por pura necessidade, ou por acaso. É importante ressaltar que, num processo criativo, as melhores descobertas surgem inusitadamente, mesmo quando se tem objetivos definidos e se provoca intencionalmente alguma coisa. Ao lado do desenvolvimento técnico que ampara, que sustenta o processo de criação, deve haver sempre um espaço vazio, um lugar aberto para o inesperado.

Acaso e necessidade se confundem. A fronteira entre os dois é indefinível. A necessidade pode fazer surgir uma imprevisível e nova forma. Mas essa nova forma surge por acaso, mesmo quando a necessidade é objetivamente provocada. Se a necessidade surge do acaso, a nova forma também é um acaso. Mas se a necessidade foi provocada, a nova forma também foi provocada, mas ainda assim surge por acaso, ou seja, podemos propor o caminho, mas não controlar o resultado. Essas formulações poderiam sintetizar um processo de criação, mas as palavras parecem não dar conta suficientemente de descrevê-lo.

Peter Brook acredita que a necessidade violenta de projetar um significado pode realmente criar uma forma imprevisível. Ela põe de lado a discussão estilística e pode produzir um momento único, imprevisto, essencial, nascido da improvisação, técnica que se origina no contador de histórias, que diante se sua platéia começa a narrar. Essa liberdade que se estabelece entre, neste caso, o narrador e o espectador, Brook compara à liberdade do romance, onde a relação entre escritor e leitor é fluida, sem entraves. Em sua visão sobre essa relação, ou seja, sobre esse campo do imaginário que se estabelece através dessa relação, está presente uma idéia de vazio como um campo de possibilidades.

Em Shakespeare residem alguns dos princípios propulsores desses esvaziamentos que, segundo Brook, tecem a trama teatral. Uma das maiores liberdades do teatro elisabetano é a ausência de cenário. A plataforma aberta, 
apenas com portas e sacadas, permitia a Shakespeare explorar o imaginário do espectador, sugerindo sucessivas imagens capazes de dar conta de todo o universo físico. Essa liberdade, todavia, acredita Brook, não estava somente na ausência de cenário, mas principalmente no favorecimento que este teatro proporcionava à passagem do mundo da ação para o mundo psíquico, das impressões interiores. Peter Brook compara essa passagem à mudança de plano no cinema: para ele uma relação ideal com um ator verdadeiro num palco sem cenário seria como a passagem contínua de um plano geral para um close. É exatamente a mobilidade desse código que lhe confere leveza, e é essa mobilidade que caracterizava o teatro elisabetano, a mesma que Brook deseja para o teatro: quanto mais mobilidade, mais flexibilidade, mais nudez, mais leveza e maior o alcance.

Esses mundos, da ação e das impressões interiores, são, na perspectiva de Brook, equivalentes do Rústico e do Sagrado, cuja irreconciliada oposição está contida em Shakespeare, e desta oposição, justamente, vêm as "perturbadoras e inesquecíveis impressões de suas peças. É por serem tão fortes que as contradições nos ferem com tanta profundidade"(BROOK, 2000: 89). Shakespeare, para Brook, contém Brecht e Beckett irreconciliados: na diversidade da sua escrita o homem é apresentado sob todos os aspectos, e a contradição é incorporada. Ele tematiza uma enorme amplitude de afetos humanos e os expõe no extremo de suas potencialidades. Seus personagens representam de modo intenso e inexorável o limite daquilo que é demasiadamente humano. Harmoniosamente ou irreconciliados, de todo modo, os contrários habitam Shakespeare. Seus textos abrigam o sublime e o grotesco, o sagrado e o rústico. A um só tempo, os opostos vivem irreconciliados porque não se anulam, e aprofundam suas contradições, e vivem harmoniosamente, pois dialeticamente se complementam. $O$ que se poderia denominar de ausência de estilo, é justamente o que torna o teatro de Shakespeare flexível, pleno de possibilidades, potente, e, portanto, vazio.

É a dinâmica shakespeareana que Brook nos sugere absorver e acompanhar. Essa dinâmica que Voltaire considerou "bárbara", porque não lhe era possível entendê-la. E a questão que Brook levanta é: onde se encontram os equivalentes dessa variedade e dessa flexibilidade do teatro elisabetano, onde se encontra aquele "teatro rico"? Para ele esse teatro rico e rústico se aproxima do teatro pobre e sagrado de Grotowski, pois ambos buscam um novo olhar, uma nova maneira de compreensão. E Brook acredita que essa busca deve ser uma necessidade permanente do teatro, pois para produzir uma nova compreensão, para estabelecer novas formas de relação com a vida, o teatro precisa experimentar formas mais diretas e reveladoras. Ele afirma que já houve um tempo em que o teatro podia ser magia, mas que nesse nosso tempo o teatro tem de ser revelador, porque o espectador não 
quer ser trapaceado, não quer o escondido, ele quer deliberadamente fazer parte do jogo do imaginário.

Num espetáculo teatral a mudança e a interferência podem ser constantes. Esse é precisamente o sentido de um vazio permanente: a qualquer momento do jogo, suas regras podem ser mudadas. Podem-se cortar cenas, acrescentar ou suprimir falas, mudar figurinos, enfim, o espetáculo teatral pode estar sempre sendo refeito, durante todo o processo de ensaios e durante toda uma temporada. Quando Brook diz que o verdadeiro ator criativo é o ator vazio, ele se refere à capacidade do ator de estar sempre buscando, sempre recomeçando, à capacidade do ator de absorver novas descobertas, e abandonar uma conquista, às vezes, na véspera de uma estréia, à capacidade do ator de não cristalizar uma forma para o personagem: "O que interessa nos atores é sua capacidade de criar marcas imprevisíveis durante os ensaios: o que decepciona num ator é quando ele é fiel à forma"(BROOK, 2000:108).

Em O Teatro e Seu Espaço, Peter Brook define o que considera um ator verdadeiramente criativo:

$\mathrm{O}$ ator realmente criativo sente na estréia um terror diferente e muito pior. Durante todo o tempo dos ensaios ele esteve explorando aspectos de um personagem que se sente serem sempre parciais, inferiores à verdade - portanto, o ator é compelido, pela honestidade de sua busca, a desistir e recomeçar, num processo infindável. Um ator criativo estará sempre disposto a se desembaraçar das formas acabadas do seu trabalho no último ensaio [...]. $O$ ator criativo também deseja agarrar-se a tudo que descobriu, também deseja a todo custo evitar o trauma de aparecer nu e despreparado perante o público - e no entanto, é exatamente isso que tem de fazer. Precisa destruir e abandonar seus resultados precedentes, mesmo que isto que agora está adotando pareça quase a mesma coisa. Isto é mais fácil para os atores franceses do que ingleses, pois os franceses são de temperamento mais aberto à idéia de que nada vale alguma coisa [no inglês nothing is any good, quer dizer, nada é tão bom]. E esta é a única maneira pela qual um papel pode nascer, ao invés de ser construído. O papel que foi construído é o mesmo todas as noites - só que lentamente se desgasta. Enquanto que, para o papel nascido ser o mesmo, ele tem sempre que renascer, o que o torna sempre diferente. (BROOK, 1970: 121-122)

Brook escreve esse texto antes da formação do CIRT e antes de se 
aventurar em suas viagens apresentando espetáculos sobre o tapete. Os frutos desta experiência reafirmaram sua perspectiva sobre o ator criativo. Um ator verdadeiramente criativo é sempre um espaço vazio. É um ator que se arrisca a abandonar as formas encontradas e fixadas, do primeiro ao último ensaio, ou durante a temporada; que é capaz de abrir mão de um gesto, de uma marca, de uma fala, de uma conquista e recomeçar. O ator vazio é um ator aberto às novas descobertas, às novas formas, um ator capaz de ser no tempo, um ator que entende que uma repetição pode ser sempre diferente, se ele estiver disposto a se recolocar.

Aqui reside, entretanto um paradoxo: repetir-se e ser ao mesmo tempo original. A tal da diferença na repetição, problemática largamente explorada pelo filósofo francês Gilles Deleuze. O grande salto da arte é aliar técnica e espontaneidade. Mas como ser espontâneo ao repetir? Nas improvisações, durante os ensaios, descobrimos espontaneamente coisas novas, e à medida que o processo vai se desenvolvendo vamos fixando essas descobertas naquilo que no teatro se chama partitura cênica. Aí começa o problema: repetir. O que sustenta a repetição é a técnica, mas a técnica não é suficiente para manter a vivacidade daquele evento, é preciso algo mais. O quê? Espontaneidade. Mesmo nos hapennings ou em espetáculos de improvisação como os carpet shows, é o próprio Brook quem afirma, a morte fica à espreita, e a qualquer momento pode tragar aquela experiência.

Um círculo vicioso? Sem saída? Certamente não. O irreconciliável habita a "natureza" do teatro. Esse é o desafio. Mudar os contextos, retirar o teatro dos edifícios teatrais, apresentar espetáculos sobre um tapete nos lugares mais variados, essa foi a maneira, encontrada por Peter Brook e seu grupo, de testar mais do que novas formas, a vivacidade das formas e os significados que elas podem alcançar.

\section{Notas}

${ }^{1}$ Brook par Brook: portrait intime. Direção: Simon Brook. 2001. (filme)

2 O Actor's Studio foi fundado em 1947 por Cheryl Crawford, Elia Kazan e Robert Lewis. Lee Strasberg, inicialmente professor do Actor's Studio, se tornou diretor da Escola em 1952, e desenvolveu ali um método baseado no Sistema de Stanislavski.

${ }^{3}$ Em 1970, Peter Brook criou juntamente com Micheline Rozan o Centro Internacional de Pesquisas Teatrais (Centre International de Recherches Théâtrales) - CIRT; Em 1974 eles fundaram o Centro Internacional de Criações Teatrais (Centre International de Créations Théâtrales) - CICT. CIRT e CICT são dois centros, de pesquisa e criação, que coexistem para uma série 
de atividades simultâneas.

\section{Bibliografia}

ARTAUD, Antonin. Linguagem e vida. tradução: J. Guinsbrug e outros. São Paulo: Perspectiva. 1995.

BRECHT, Bertol. Teatro dialético. tradução: Luis Carlos Maciel. Rio de Janeiro: Editora Civilização Brasileira, 1967.

BROOK, Peter. O teatro e seu espaço. tradução: Oscar Araripe e Tessy Calado. Petrópolis: Vozes, 1970.

. O ponto de mudança: quarenta anos de experiências teatrais: 1946-1987. tradução: Antônio Mercado e Elena Gaidano. Rio de Janeiro: Civilização Brasileira, 1994.

. The open door - thoughts on acting and theatre. New York: Theatre Communications Group, 1995.

The empty space. New York: Touchstone, 1996.

. Fios do tempo: memórias. tradução: Carolina Araújo. Rio de Janeiro: Bertrand Brasil, 2000.

CAMUS, Albert. O mito de Sísifo: ensaio sobre o absurdo. tradução: Mauro Gama. Rio de Janeiro: Editora Guanabara, 1989.

CHENG, François. Vide et plein - le langage pictural chinois. Paris: Éditions du Seuil, 1991.

CONRADO, Aldomar (org.).O teatro de Meyerhold. tradução: Aldomar Conrado. Rio de Janeiro: Civilização Brasileira, 1969.

GROTOWSKI, Jerzy. Em busca de um teatro pobre. tradução: Aldomar Conrado. Rio de Janeiro: Civilização Brasileira, 1987.

KOTT, Jan. Shakespeare nosso contemporâneo. tradução: Paulo Neves. São Paulo: Cosac \& Naify, 2003.

NIETZSCHE, Friedrich Wilhelm. A gaia ciência. tradução: Márcio Pugliesi, Edson Bini e Norberto de Paula Lima. Rio de Janeiro: Ediouro, s/d.

OIDA, Yoshi. Um ator errante. tradução: Marcelo Gomes. São Paulo: Beca, 1999.

ROSSET, Clément. Alegria: a força maior. tradução: Eloisa Araújo Ribeiro. Rio de Janeiro: Relume Dumará, 2000.

\section{Referência Filmográfica}

Brook par Brook, portrait intime. Direção: Simon Brook. 2001. 